\title{
A New Spray Mixing Model of Quasi-Dimensional Model for Diesel Engine Working Process
}

\author{
Kunpeng $\mathrm{Qi}^{1 \text {, a }}$, Wuqiang Long ${ }^{2, \mathrm{~b}}$, Jisheng $\mathrm{Hu}^{1, \mathrm{c}}$ \\ ${ }^{1}$ School of Traffic and Transport Engineering, Dalian JiaoTong University, Dalian 116028, China \\ ${ }^{2}$ Institute of Internal Combustion Engine, Dalian University of Technology, Dalian 116023, China \\ aqikp@sina.com, ${ }^{\mathrm{b}}$ longwuqiang2004@163.com, 'bssmd@126.com
}

\begin{abstract}
Keywords: Phase-divided Spray Mixing Model; Quasi-dimensional Model; Diesel Engine Working Process; MATLAB/Simulink

Abstract. In order to satisfy the validity demand of quasi-dimensional combustion model for predicting diesel engine performance, a new phase-divided spray mixing model is proposed in this work. The software MATLAB/Simulink is utilized to build the quasi-dimensional combustion model of diesel engine working process, and the performance for diesel engine is simulated. The comparisons between calculated results and experimental data show that the relative error of power and brake specific fuel consumption is less than $2.3 \%$, and the relative error of nitric oxide and soot emissions is less than $5.8 \%$. The good agreement between experimental results and calculated results indicates that the quasi-dimensional model of diesel engine working process which is based on the phase-divided spray mixing model is reliable for predicting power, fuel consumption and emissions of diesel engine.
\end{abstract}

\section{Introduction}

In recent years, because of the high demand for improving power, fuel consumption and emissions of diesel engine, the functions of diesel engine control system have become more complex than ever before. Accordingly, development process of diesel engine is increasingly complicated and this does lead to even higher time and money cost. With the development of computer techniques and the basic theory research on computational fluid dynamics, heat transfer, chemical dynamics, etc., working process simulation has become an increasingly important development tool for diesel engine. Simulation of diesel engine working process by the utilization of diesel engine model is useful in developing diesel engine control system, reducing experimental work, saving experimental expense and shortening experimental period.

Currently, the quasi-dimensional model for diesel engine working process is one of the most popular models being applied to simulate the diesel engine working process and its central part is the spray mixing model. As results of many years of hard research, varieties of spray mixing models of diesel engine have developed, such as fuel droplets evaporation model proposed by Hiroyasu firstly [1-4], transient gaseous flow model proposed by Lyn firstly [5-6] and two-phase flow model proposed by Jin [7-9]. In the fuel droplets evaporation, it assumed that the combustion is controlled by the fuel droplets evaporation considering the fuel atomization and gasification processes. Therefore, atomization process as well as evaporation process of fuel droplets was taken into account. Since the spray was divided into a large number of zones and evaporation rate of fuel droplets had to be calculated in each time step, the calculation with the fuel droplets evaporation model was very time-consuming. In the transient gaseous flow model, it assumed that only the gaseous phase fuel existed in the combustion chamber due to the high pressure in it which caused the fuel droplets evaporated instantaneously, thus the combustion was determined by the mixing of fuel vapor and fresh air. Because the spray was simplified as a gaseous spray in this model, the computation of model was simpler, but the instantaneous evaporation of the fuel injected into the combustion chamber was not quite accurate. Considering the evaporation of fuel droplets and neglecting the relative movement between the droplets and air entrainment, it assumed that the fuel injected at a calculation time step approximates isoconcentration after some time period and the two-dimensional 
flow is simplified as a one-dimensional flow in the two-phase flow evaporation model. But the model is still complex for fuel droplets evaporation computation although the spray mixing process is simplified.

In this work, a new phase-divided spray mixing model was presented to calculate the fuel-air mixing process in order to simplify the quasi-dimensional model for diesel engine working process. The model assumed that the fuel injected into combustion chamber at a calculation time step is liquid droplets in break-up period, and becomes gaseous spray after break-up period. The two-dimensional spray mixture flow is regarded as a one-dimensional flow after break-up period. Consequently, a simplified quasi-dimensional model of diesel engine working process is obtained.

\section{Spray mixing model}

Phase-divided spray mixing model. In this model, the basic principle is that the fuel in combustion zones is in liquid phase during break-up period and turns to gaseous phase after break-up time. The air begins to entrain into the combustion zones after break-up time and the two-dimensional flow is simplified as a one-dimensional flow.

The following basic assumptions are included in the phase-divided spray mixing model: (1) The combustion chamber is divided into an air zone $A$ and many combustion zones $B_{i}$ which are made up of the fuel injected into combustion chamber, the fresh air entrained into the zone and the burning products at each calculation time step. The number of combustion zones equals the number of time step during fuel injection period. (2) During break-up period, the injected fuel atomizes and evaporates. No fresh air is entrained into combustion zones in this period, and air entrainment is assumed to start after break-up time. The fuel-air mixture becomes isoconcentration after break-up time, and the two-dimensional flow is simplified as a one-dimensional flow. (3) The amount of air entrained into the combustion zone is calculated based on the fuel momentum when it is injected and the momentum remains the same during mixing process. (4) Fuel mixes with entrained air according to the stoichiometric fuel-air ratio in combustion zones, and partial burning is neglected here. (5) There is no fresh air entrained into combustion zone after the fuel in this zone is burnt out. With these assumptions, the spray mixing model is simplified and the computational time of phase-divided spray mixing model is shorter.

Division principle of the zonal boundary. The concentration distribution line of spray in stable region of gaseous flow is given by Eq. (1) ${ }^{[10]}$ :

$$
\frac{C}{C_{M}}=1-\left(\frac{r}{r_{0}}\right)^{1.5}
$$

The calculation equation of r0is given by Eq. (2) ${ }^{[11]}$ :

$$
r_{0}=x \cdot \operatorname{tg} \frac{\theta}{2}
$$

The transient isovelocity line of spray in stable region of gaseous flow is given by Eq. (3) ${ }^{[10]}$ :

$$
\frac{u}{u_{M}}=\left[1-\left(\frac{r}{r_{0}}\right)^{1.5}\right]^{2}
$$

The relationship between isoconcentration line of spray and transient isovelocity line of spray is:

$$
\frac{C}{C_{M}}=\frac{\sqrt{u}}{\sqrt{u_{M}}}=1-\left(\frac{r}{r_{0}}\right)^{1.5}
$$

From Eq. (4), it can be concluded that the axial isovelocity line of spray along radial direction in stable region of gaseous flow is the isoconcentration line of spray at the same moment, so the axial isovelocity line of spray along radial direction in stable region of gaseous flow can be used to substitute the isoconcentration line of spray for dividing the boundary of combustion zone. 
According to the research on relativity [12], the momentum of transient flow across the isoconcentration line can be expressed with an average velocity, and the ratio between the average velocity and the front velocity in the centerline of transient flow is 0.584 . So the isoconcentration line of spray " $C=f(x, r)$ " is substituted by the zonal average velocity " $u_{j}=0.584 u_{c j}=f(x)$ " which leads the simplification of the two-dimensional flow into a one-dimensional flow.

The front velocity in the centerline of transient flow is given by Eq. (5) ${ }^{[11]}$ :

$$
u_{c j}=u_{M}=\frac{d S}{d t}=1.475 \cdot \sqrt[4]{\frac{p_{i n j}-p}{\rho}} \cdot \sqrt{\frac{d_{0}}{t}}
$$

Considering the differences of pressure and density of transient working fluids in cylinder between each calculation time step after break-up period, the calculation method of spray tip penetration after break-up period in the $k$ th calculation time step is proposed as follows:

$$
\begin{aligned}
& S=S_{b}+\sum_{j=1}^{k}(\Delta S)_{j} \\
& u_{0}=0.39 \cdot \sqrt{\frac{2 \cdot\left(p_{i n j}-p\right)}{\rho_{l}}} \\
& S_{b}=u_{0} \cdot t_{b} \\
& (\Delta S)_{j}=u_{c j} \cdot \Delta t \\
& \Delta t=\Delta \varphi /(6 n)
\end{aligned}
$$

Fig. 1. shows the diagram of zonal boundary in the phase-divided spray mixing model when the fuel injection duration is $7^{\circ} \mathrm{CA}$. In this diagram, the zonal boundary of $\mathrm{B}_{5}, \mathrm{~B}_{6}, \mathrm{~B}_{7}$ do not appear because the fuel in these zones are still in break-up period.

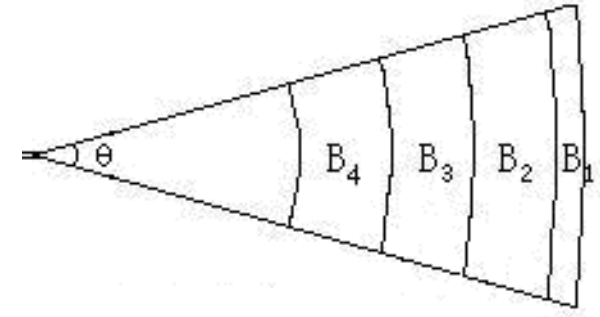

Fig.1 Schematic diagram of zone division of phase-divided spray mixing model

Air entrainment calculation. The amount of air entrainment is calculated in accordance with the momentum conservation principle as follows ${ }^{[9]}$ :

$$
\begin{aligned}
& m_{f i} u_{o i}=\left(m_{f i}+m_{a i j}\right) u_{j} \\
& u_{o i}=0.39 \sqrt{\frac{2 \cdot\left(p_{i n j}-p_{a}\right)}{\rho_{l}}} \\
& u_{j}=0.584 \cdot u_{c j} \\
& m_{a i j}=m_{a i(j-1)}+\Delta m_{a i j}
\end{aligned}
$$

When combustion starts in a mixing zone, there is a reduction of the air entrainment quantity in the model. The air entrained into a burning mixing zone is given by Eq. (15) ${ }^{[9]}$ :

$$
\Delta m_{a i j}{ }^{\prime}=c_{a} \cdot \Delta m_{a i j}
$$

\section{Simulation of quasi-dimensional model for diesel engine working process}

The quasi-dimensional combustion model of diesel engine is developed based on the phase-divided spray mixing model, and it includes break-up time calculation, air entrainment calculation, ignition 
delay period calculation, heat transferring calculation, thermodynamics calculation, combustion products calculation and emissions calculation ${ }^{[12]}$.

Experiment results were obtained from the 1135 naturally aspirated diesel engine for comparison with the calculated results. The specifications of the diesel engine are listed in Table 1.

Table1 1135 diesel engine specifications

\begin{tabular}{cc}
\hline Parameters & Value \\
\hline Cylinder diameter $/ \mathrm{mm}$ & 135 \\
Stroke $/ \mathrm{mm}$ & 150 \\
Rated speed $/ \mathrm{r} \cdot \mathrm{min}^{-1}$ & 1500 \\
Rated power $/ \mathrm{kW}$ & 14.7 \\
Compression Ratio & 17 \\
Cylinder work volume/L & 2.15 \\
Residual exhaust gas coefficient & 0.05 \\
Swirl ratio & 1.2 \\
\hline
\end{tabular}

The comparison of the calculated and experimental cylinder pressure at rated condition is shown in Fig.2. It can be seen that the two cylinder pressure curves show good agreement which means the quasi-dimensional model of diesel engine working process based on a new phase-divided spray mixing model represented in this work is qualified to simulate the combustion process of diesel engine. The cause of difference between calculated and experimental cylinder pressure curves is that the fuel is burned at the theoretical fuel-air equivalence ratio in the quasi-dimensional model contrasting with normally insufficient combustion in real diesel engine working process.

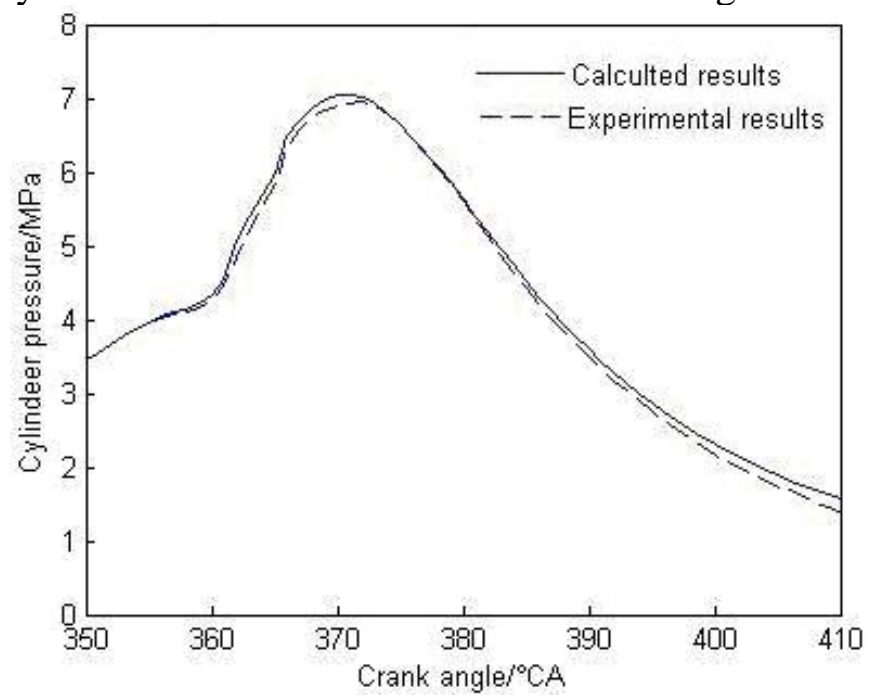

Fig. 2. Comparison of the calculated and experimental cylinder pressure at rated condition

The comparison of the calculated and experimental diesel engine performance at rated condition is shown in Table 2. It can be observed that the maximum relative error of power and fuel consumption between experimental and calculated results is less than $2.3 \%$, and the maximum relative error of NOx and soot between experimental and calculated results is less than 5.8\%.

Table 2 Comparison of calculated and experimental diesel engine performance at rated condition

\begin{tabular}{cccc}
\hline Item & Calculated results & Experimental results & Relative error \\
\hline Power $/ \mathrm{kW}$ & 15.0051 & 14.7 & $2.1 \%$ \\
fuel consumption $/ \mathrm{g} \cdot \mathrm{kW}^{-1} \cdot \mathrm{h}^{-1}$ & 240.0182 & 245 & $2.3 \%$ \\
$\mathrm{NOx} / 10^{-6}$ & 1176 & 1246 & $5.6 \%$ \\
Soot $/ \mathrm{BSU}$ & 1.8729 & 1.77 & $5.8 \%$ \\
\hline
\end{tabular}


From the observation of Table2, it can be concluded that the agreement between experimental results and calculated results of diesel engine performance is good. The cause of difference between experimental and calculated results of diesel engine power and fuel consumption is that the assumption of neglecting the mass decrease due to the leakage during factual diesel engine working process. The cause of difference between experimental and calculated results of diesel engine NOx and soot is that the selecting of coefficient is not quite accurate in the quasi-dimensional model of diesel engine working process which can be studied further.

\section{Conclusions}

In this paper, a quasi-dimensional combustion model of diesel engine is proposed, which is based on the new simplified phase-divided spray mixing model. The simulation results of the model have good accordance with experimental data which proves the validation of the phase-divided spray mixing model and its related assumptions. Since the fuel-air mixing process is simplified, the calculation time of mixing process is largely reduced compared with other spray mixing models, which means the real time operating performance of the simulation model is greatly improved.

\section{References}

[1] H. Hiroyasu, T. Kadota: Models for Combustion and Formation of Nitric Oxide and Soot in Direct Injection Diesel Engines. SAE paper 760129, 1976.

[2] D.T. Hountalas, D.A. Kouremenos, G.C. Macropoulos, et al., Multi-Zone Combustion Modeling as a Tool for Di Diesel Engine Development-Application for the Effect of Injection Pressure, SAE Paper 2004-01-0115, 2004.

[3] E.G. Pariotis, D.T. Hountalas, Validation of a Newly Developed Quasi-Dimensional Combustion Mode-Application on a Heavy-Duty Di Diesel Engine, SAE Paper 2004-01-0923, 2004.

[4] R. Udayakumar, M.S. Anand, Multizone Combustion Model for a Four-Stroke Direct Injection Diesel Engine, SAE Paper 2004-01-0921.

[5] W. S. Chiu, S. M. Shahed, W. T. Lyn: A Transient Spray mixing Model for Diesel combustion. SAE paper 760128, 1976.

[6] A.S. Kuleshov, Use of Multi-Zone DI Diesel Spray Combustion Model for Simulation and Optimization of Performance and Emissions of Engines with Multiple Injection, SAE Paper 2006-01-1385, 2006.

[7] G.D. Jin, A simplified vaporizing and mixing model for diesel spray two-phase flow, Transactions of CSICE, Vol. 1-6(1986), p. 143 (In Chinese).

[8] X.P. Bi, M.G. Yang, S. Han, A Multi-Zone Model for Diesel Spray Combustion, SAE Paper 1999-01-0916, 1999.

[9] X.P. Bi, S. Han, Z.L. Dai, et al., A Multi-Zone Model for Prediction of Di Diesel Engine Combustion and Soot Emission, SAE Paper 941900, 1994.

[10] F.J. Zhu, J. Wu, Numerical Simulation and its Optimization of Internal Combustion Engine Working Process(National Defense Industry Press, China 1997) (in Chinese).

[11] H. Hiroyasu, T. Kadota, M. Arai, Development and use of a spray combustion modeling to predict diesel engine efficiency and pollutant emission, JSME Vol.26 (1983),p. 569.

[12] G.D. Jin, Z.A. Cai, A preliminary investigation on combustion model for direct injection diesel engines, Transactions of CSICE Vol. 1-6(1986), p. 33 (In Chinese). 